\title{
“No es muletilla, es marCAdor, ¿CACHÁI?". AnÁlisis DE LA FUNCIÓN PRAGMÁTICA DEL MARCADOR DISCURSIVO CONVERSACIONAL CACHÁI EN EL ESPAÑOL DE CHILE ${ }^{1}$
}

\author{
Lissette Andrea Mondaca Becerra*** \\ Andrea Patricia Méndez Carrasco ${ }^{* *}$ \\ Marcela Jonely de Lourdes Rivadeneira Valenzuela****
}

\section{Resumen}

Esta investigación tiene por objetivo analizar las funciones pragmáticas asociadas al uso del marcador discursivo conversacional cachái y su relación con variables extralingüísticas (sexo y procedencia geográfica). Para esto se utilizó un corpus de entrevistas sociolingüísticas extraídas de un proyecto de investigación Fondecyt. Los resultados obtenidos permiten corroborar la existencia de relación entre el uso de cachái y el factor procedencia geográfica, mientras que la variable sexo no parece influir en el empleo del marcador.

Palabras clave: Marcadores discursivos, cachái, variación lingüística, español de Chile.

\section{“IT IS NOT A TAG, IT IS A MARKER, CACHÁI?" PRAGMATIC FUNCTION ANALYSIS OF THE CHILEAN CONVERSATIONAL DISCOURSE MARKER CACHÁI}

\begin{abstract}
This research aims to analyze the pragmatic functions associated with the use of the Chilean conversational discourse marker cachái and its relationship with extralinguistic variables, (sex and geographical origin). In order to achieve this goal a spoken corpus of sociolinguistic interviews extracted from a Fondecyt research project was used. The results allow us to confirm the existence of a relationship between the use of cachái and the geographical origin variable, while the sex variable does not seem to have an influence in the use of the marker.
\end{abstract}

Keywords: Discourse markers, cachái, linguistic variation, Chilean Spanish.

Recibido: 12-01-2015

Aceptado: 01-04-2015

1 El presente artículo forma parte de la tesis de Licenciatura en Traducción realizada por las dos primeras autoras, cuyo trabajo se enmarca dentro del proyecto Fondecyt 11110211 El voseo en Chile. Un cambio lingüístico en desarrollo. Aspectos internos y externos de la variación, dirigido por Marcela Rivadeneira.

** Chilena. Licenciada en Traducción, Universidad Católica de Temuco, Temuco, Chile. amendez2008@ alu.uct.cl

*** Chilena. Licenciada en Traducción. Universidad Católica de Temuco, Temuco, Chile. Imondaca2010@ alu.uct.cl

**** Chilena. Doctora en Ciencias del Lenguaje y Lingüística Aplicada. Académica de la Universidad Católica de Temuco, Temuco, Chile.mrivadeneira@uct.cl 


\section{Introducción}

En la conversación existen diversos factores o elementos que ayudan a la cohesión del texto y que además dan al hablante la posibilidad de crear enunciados fluidos. Los marcadores discursivos, unidades lingüísticas invariables que no ejercen una función sintáctica preestablecida (Martín Zorraquino y Portolés, 1999), están presentes día a día en los enunciados que emitimos, precisamente con el objetivo de guiar la conversación, otorgándole ciertos matices que, si bien no afectan su sentido global, sí la dotan de intenciones diferentes. En este sentido, el español de Chile posee rasgos característicos que le permiten diferenciarse de otras variedades dialectales del español (Benavides, 2003; Cerny, 1999). En nuestro país, existe un marcador discursivo conversacional que se utiliza de forma masiva y para diversos propósitos; sin embargo, no ha sido estudiado a fondo desde el punto de vista de su función pragmático-discursiva. Se trata del marcador discursivo cachái. En el presente estudio se pretende identificar y describir las funciones pragmático-discursivas asociadas a este marcador conversacional en un corpus oral de español de Chile recopilado dentro del proyecto Fondecyt "El voseo en Chile: un cambio lingüístico en desarrollo. Aspectos internos y externos de la variación". Realizar una investigación de este tipo contribuye en gran manera a los estudios sobre marcadores discursivos que se han realizado en Chile, los que se han enfocado principalmente en el habla capitalina (Pons y Samaniego, 1998; San Martín, 2011; Gille, 2013a, 2015a, 2015b; Valencia, 2014), existiendo hasta la fecha solo un trabajo en una zona geográfica diferente, concretamente en la ciudad de Valdivia (Poblete, 1998). De esta forma, el presente estudio tiene la particularidad de incluir la variable geográfica, en tanto se abarca Chile en sus distintas áreas dialectales, y así se analiza la función que cumple el marcador discursivo cachái a nivel territorial como comunidad de habla. La investigación que se realizó es de corte exploratorio, ya que los datos corresponden solo a una porción del corpus dentro del cual se enmarca.

\section{Marco teórico}

\subsection{Marcadores del discurso}

Los marcadores discursivos son partículas que están presentes en todas las lenguas y en cada una de ellas cumplen funciones pragmáticas 
en el discurso. Martín Zorraquino y Portolés (1999) proponen la siguiente definición para los marcadores del discurso:

Son unidades lingüísticas invariables, que no ejercen una función sintáctica en el marco de la predicación oracional y poseen un cometido coincidente en el discurso: el de guiar, de acuerdo con sus distintas propiedades morfosintácticas, semánticas y pragmáticas, las inferencias que se realiza en la comunicación. (p. 4057)

Además, Martín Zorraquino y Portolés (1999) proponen algunas características definitorias para los marcadores discursivos: desde la prosodia, estas unidades son definidas por la entonación; sin embargo, en la escritura con frecuencia esta entonación se refleja al ubicar el marcador entre comas. Morfológicamente, son unidades lingüísticas que no varían y que pertenecen a diferentes categorías gramaticales, como interjecciones, adverbios o locuciones. Sintácticamente, son unidades que no están integradas en la oración y no presentan una posición preestablecida o definida dentro de esta, ya que pueden situarse en posición inicial, intermedia o final. Sin embargo, y como en todo orden de cosas, hay excepciones en las que ciertos marcadores sí ocupan una posición específica dentro de la oración. Finalmente, desde el punto de vista de la semántica, son elementos que no presentan un contenido referencial o denotativo, sino que cumplen la función de guiar las inferencias que se presentan en la situación comunicativa.

Para clasificar el marcador cachái dentro de una categoría según su función fueron fundamentales los estudios sobre marcadores del discurso realizados por Martín Zorraquino y Portolés (1999) y Portolés (2001). Martín Zorraquino y Portolés (1999: 4051-4213) distinguen cinco tipos de marcadores discursivos: estructuradores de la información, conectores, reformuladores, operadores argumentativos y conversacionales. Según esta clasificación, el marcador discursivo que es objeto de nuestro de análisis entra en la categoría de marcadores conversacionales. Dichos marcadores manifiestan la relación entre los participantes de la conversación y de éstos con sus enunciados, además permiten reforzar o justificar los razonamientos de los hablantes ante su(s) interlocutores(es), con el fin de mantener o comprobar el contacto o como elementos que implican al interlocutor de forma activa (Briz 2001: 224-225, citado en San Martín, 2011: 139). 
Según lo propuesto por Martín Zorraquino y Portolés (1999), el término marcador conversacional resulta más apropiado para denominar estas partículas del discurso, debido a que abarca unidades lingüísticas capaces de realizar diversas funciones, tales como: conectar dos miembros discursivos, servir como estructuradores de la información o limitar al hablante a introducir un comentario al margen, respecto de algo dicho anteriormente. Los mismos autores clasifican los marcadores discursivos en cuatro categorías: modalidad epistémica, relacionados con el grado de conocimiento, certeza o no certeza de los hablantes; modalidad deóntica, actitudes relacionadas con la voluntad o lo afectivo; enfocadores de alteridad, útiles para situar al hablante respecto a su interlocutor; y metadiscursivos conversacionales, útiles para organizar información o mantener el turno dentro de la conversación.

\subsection{Estudios sobre marcadores conversacionales}

En lo que respecta a estudios sobre marcadores del discurso en español, encontramos el trabajo de Briz (1998), quien en su libro El español coloquial en la conversación dedica un capítulo a las estrategias de conexión y formulación y hace referencia a los marcadores metadiscursivos de control de contacto. Según este autor, la función interpersonal destaca sobre las otras funciones en la conversación. Rodríguez (2009), por su parte, realiza un trabajo centrado en las funciones pragmadiscursivas de las partículas “¿no?” y “¿eh?” en el español hablado. Finalmente, destacamos el trabajo de Móccero (2010) quien analiza las preguntas confirmatorias como indicadoras de posicionamiento intersubjetivo.

Antes de establecer y definir las funciones que cumple el marcador discursivo cachái en el español de Chile, es apropiado revisar otros estudios sobre marcadores discursivos realizados en nuestro país. San Martín (2011) realiza una aproximación variacionista de los marcadores interrogativos de control de contacto en un corpus de entrevistas sociolingüísticas de la ciudad de Santiago de Chile. El estudio, basado en informantes estratificados socialmente, concluye que cachái es el marcador conversacional más frecuente, con una significación estadística marcadamente amplia. A su vez, Pons y Samaniego (1998) realizan un trabajo basado en la detección, descripción y análisis de los marcadores pragmáticos de apoyo discursivo utilizados en el discurso oral de los hablantes cultos de Santiago. De las diferentes categorías propuestas por 
los autores destaca la de tipo finalizador y, dentro de esta, los marcadores solicitadores de aprobación, donde se indica que cachái es uno de los que se utiliza con mayor frecuencia. Valencia (2014) analiza las preferencias en el uso de marcadores en el discurso oral de profesionales universitarios santiaguinos con el fin de constatar tendencias en la modalidad discursiva y comprobar la influencia de los cambios sociales ocurridos en Chile en un período de tiempo determinado. Cid y Poblete (1999) dan cuenta del comportamiento prosódico de los marcadores que, a nivel discursivo, ayudan a la cohesión del significado en su globalidad y postulan que el valor pragmático de los marcadores se determina por el comportamiento prosódico que los acompaña. Poblete (1998) estudia los marcadores del discurso empleados en Valdivia. Rabanales y Contreras (1991), por su parte estudian las muletillas en el habla culta de Santiago de Chile. Meneses (2000) investiga los marcadores discursivos en la conversación, vista por la autora como uno de los eventos comunicativos fundamentales. Finalmente, González, Meneses y Unda (2000) realizan un análisis de la relación entre estructuras sintácticas y marcadores discursivos en la conversación semiespontánea de adolescentes santiaguinos.

El principal exponente en el área de las investigaciones sobre el marcador discursivo cachái en Chile es Johan Gille, autor de origen sueco quien en sus diversas publicaciones realiza un estudio exhaustivo del uso y función de este marcador conversacional (Gille, 2013a 2015a, $2015 b$ ). Este autor describe las funciones interactivas del marcador cachái y centra su análisis en la identificación de una base pragmática del marcador, sobre la cual se sustentan los usos de este. En sus estudios, el autor propone seis funciones para el marcador cachái: llamada de atención (función base), gestión intersubjetiva, organización discursiva, autorregulación, negociación de turno y distribución de roles (Gille, 2015b). Cabe señalar que si bien Gille define la llamada de atención como la principal función del marcador cachái, esta se encuentra presente en todas las demás. 


\subsection{Origen y evolución de cachái}

Morfológicamente la forma cachái proviene del verbo cachar, presenta flexión voseante en presente de indicativo y no puede conjugarse con ninguna otra forma de segunda persona del singular². Es decir, su uso es restrictivo a la morfología del voseo chileno (Rivadeneira, 2014). Sin embargo, existen varias dudas respecto a su origen etimológico. Según la Real Academia de la Lengua Española (2001) cachar proviene del préstamo del verbo inglés to catch. Una propuesta alternativa es la que señala Gille (2015b), en tanto cachar provendría del verbo de español medieval catar (Lenz, 1905), el que a su vez proviene del étimo latino captare - tratar de percibir por los sentidos, en especial la visión y oídos (Corominas, 1954). Así, catar se combina con los adverbios locativos 'aquí' y 'ahí' (cata ahíl aquí), lo que resulta en expresiones como 'mira aquí/ahí'. Gille (2015b:5) además propone un tercer y último origen como candidato posiblemente más adecuado. Para el autor, cachar proviene del verbo catar o catear, derivado de la siguiente forma catear $>$ catiar $>$ cachar. Cabe señalar que a principios del siglo XX las tres formas coexistieron en la escritura chilena. Por otra parte, desde el punto de vista semántico, según el diccionario del uso del español de Chile (Academia de la Lengua, 2010), respecto al verbo cachar se conocen cuatro acepciones distintas: percibir con la visión o los oídos; conocer, tener conocimiento; entender, comprender y suponer, creer.

\subsection{Funciones pragmáticas del marcador discursivo cachái}

Las definiciones de las distintas funciones del marcador discursivo conversacional cachái que se elaboran en este estudio se basan parcialmente en las propuestas de San Martín (2011), Pons y Samaniego (1998) y Gille (2015b). A continuación se expone el listado de las cinco funciones básicas que cumple el marcador discursivo cachái y sus definiciones, ambas presentadas como una propuesta de análisis en el presente estudio:

2 A este respecto, lo normal en la interacción oral es que se conjugue siempre mediante flexión voseante y no así con tuteo (cachas) o ustedeo (cacha). 


\section{1. 'Cachái' como captador de atención}

Es la función base de cachái y busca mantener el contacto entre los interlocutores. Es importante señalar que todo marcador cachái empleado en el discurso tiene un carácter fático, independiente de que en él se puedan apreciar otras funciones. Veamos a modo de ejemplo un caso extraído del corpus ${ }^{3}$ :

(1) M2B7: Le hizo así seguro, no sé, yo me imagino porque nunca he sabido realmente cómo había sido y al otro día sale en las noticias que la misma gente de ahí, los fileteros, y le habían sacado el cuchillo.

Entrevistador: Ya.

M2B7: Como súper orgullosos de eso, CAcachái $\rightarrow$, que le habían sacado el cuchillo y el pelícano se fue volando así. Yo cacho que más allá se tiene que haber muerto el pelícano.

Entrevistador: Que voló dos metros y se-

M2B7: Sí poh.

En el ejemplo, el marcador cachái es empleado con el fin de mantener el contacto entre los interlocutores. El emisor lo utiliza para que el receptor preste atención a lo que está diciendo. La marca prosódica en este caso $[\rightarrow]$ indica la entonación neutra del marcador, es decir, que no hay un cambio en la melodía del discurso.

\section{2. 'Cachái' como solicitador de aprobación}

Esta función permite al emisor compartir una información e invitar al receptor a aprobar, afirmar y/o compartir lo dicho a través del marcador. En este caso, cachái sería equivalente a un “¿me entiendes?”. Además, cabe señalar que esta función también se puede dar en secuencias narrativas explicativas o incluso instructivas para asegurar comprensión del enunciado.

(2) Entrevistador: Nada, nada, de hecho yo como a las tres de la tarde empiezo como que ya empiezo la normalidad, pero todo el periodo de la mañana es como, me duele la guata, tengo sueño, tengo hachazo.

3 En el ejemplo se mantiene la etiqueta asignada al informante en el corpus general del cual se extraen los datos. En ese caso, se trata de una mujer (M) de Iquique (2), del grupo generacional adulto joven (B). 
M3A7: Es que bueno, es que como yo no tomo, como que el hachazo y el dolor de guata ya no ¿SAcachái?^

Entrevistador: Ah, claro, no, yo hubo un tiempo que tomé harto.

En el ejemplo anterior, el hablante utiliza el marcador cachái para compartir una información con su interlocutor y lo invita a intervenir en la conversación. Las marcas prosódicas [ $[$ ] indican la entonación ascendente que se da al marcador mediante la marca de interrogación.

\section{3. 'Cachái' como herramienta argumentativa}

Mediante el uso de cachái como herramienta argumentativa el emisor refuerza lo que enuncia. Esta función se da en secuencias donde el emisor propone una idea y utiliza el marcador para reforzarla y argumentar su punto de vista, para lo cual muchas veces se acude al uso de otros elementos lingüísticos que sirven de apoyo discursivo; por ejemplo, a través de adjetivos o ejemplificaciones.

(3) Entrevistador: Pero ¿te gusta el neandertal, ser más prominente, harto pelo?

M3A7: Estai [...], hueón, tiene, así como cejas para regalarle al mundo, hueón, así como-

Entrevistador: (Risas).

M3A7: Y como-tiene como tres cejas, ¿SAcachái $\uparrow$, en una, ¿hai cacha'o? Es como hasta acá hueón, una ceja así gigante, yo creo que debe ser así-

Entrevistador: Hombre cejudo.

M3A7: No es, no es ya, no es una ceja ¿HAcachái?^, pero es como grande, grande, así como-

En el ejemplo anterior, el hablante utiliza el marcador cachái para reforzar la idea planteada. Este ejemplo además demuestra el uso de adjetivos junto al marcador para reforzar un argumento ("pero es como grande, grande"). La marca prosódica [ $\uparrow]$ indica la entonación ascendente que el hablante dio al marcador.

\section{4. 'Cachái' como organizador discursivo}

Esta función se presenta en secuencias narrativas o en cambios de planos discursivos. El hablante, mediante el uso de cachái puede, de 
cierta forma, establecer el cambio de un plano discursivo a otro (Gille, 2015b), como sucede durante el discurso referido, o narrar una secuencia de hechos.

(4) Entrevistador: Oye, pero por ejemplo, ¿cada campus tiene su directiva o no?

H6B10: No, no, es que era una orgánica que se había creado, se creó en, primero se trabajó, no me acuerdo de los primeros trabajos, pero era bien desordenado, luego se trató de crear una orgánica ODcachá $i \rightarrow$ con una mesa operativa ODcachái $\rightarrow$ con representantes de cada campus y más una mesa que eran como tres locos, dos de pedagogía en historia y otro de trabajo social, dos de trabajo social y representantes de campo que eran-que se elegían.

En el ejemplo anterior, el hablante realiza una narración que deriva de un hipertema (la "directiva") y por medio del marcador cachái organiza su enunciado (una "orgánica", una "mesa operativa", etc.).

\section{5. 'Cachái' como autorregulador}

La función de autorregulador permite que el emisor autorreformule su enunciado. En otras palabras, corrige lo que enunció o introduce otra idea. Para esto muchas veces utiliza marcadores de reformulación como o sea, onda o como que.

(5) H2B11: El día jueves, ya, vuelvo a hacer clases en la mañana, ¿ODcachái?, en la tarde quedo libre y el viernes hago clases como hasta las cuatro de la tarde.

Entrevistador: Ya.

H2B11: Entonces, igual es como, ¿AUcachái?^, o sea, tampoco es tan así como que-de repente me faltan más proyectos, más cosas, ¿SAcachái?, como pa' poder yo también tener más estabilidad, de repente pegarme la [...] también.

Entrevistador: Ya.

H2B11: Porque quiero como irme de donde mi mamá en algún momento.

En el ejemplo anterior el hablante utiliza junto a cachái un marcador de reformulación, en este caso, o sea, para reestructurar su enunciado. 


\section{El caso particular de 'cachái que'}

Cumpliendo la función de captador de atención además se encontró la locución cachái que. A nivel prosódico, esta forma es siempre neutra $[\rightarrow]$ y suele presentarse en posición inicial o intermedia dentro del enunciado. Esta locución cumple tanto función verbal como de marcador discursivo. En tales casos, su función como marcador se establece claramente en su uso por excelencia, es decir, la llamada de atención.

(6) M3B7: Claro poh, estás como que, como que aminorai su masculinidad no sé.

Entrevistador: Sí.

M3B7: Porque CAcachái que $\rightarrow$ yo una vez hice eso, CAcachái $\rightarrow$, con un gallo como que me gustaba.

En el ejemplo, la locución cachái que se utiliza para introducir una información. Cumple la función verbal semejante a un sabih que o sabes que y a la función marcadora del discurso que es captar la atención del interlocutor. De este modo el hablante implícitamente incita al receptor a prestar atención a su enunciado. Dadas estas características, esta categoría podría insertarse dentro de la función (1), captador de atención.

Además de las cinco funciones básicas mencionadas anteriormente, existen casos donde es difícil determinar la función específica que cumple cachái en el enunciado, sobre todo cuando puede apreciarse más de una intención. Este marcador cuenta con tres funciones mixtas que se presentan a continuación:

\section{6. 'Cachái' como solicitador de aprobación y herramienta argumentativa}

(7) Entrevistador: Yo lo había pensado ya urbano, así como calle.

H2B11: No, yo dejé todo eso.

Entrevistador: Era muy obvio, era muy evidente, ya, sí.

H2B11: Dejé todo lo urbano, porque quise hacer algo que incluso, que a muchos les iba a parecer como súper, eh, era algo que yo sé que a mucha gente le iba a parecer como muy, eh, abyecto, ¿SAHAcachái? $\uparrow$ Pero a mí eso abyecto me interesaba, porque era como decirle un poco que esos esclavos estaban ahí en la memoria, ¿SAHAcachái? $\uparrow$

Entrevistador: Ya. 
En el ejemplo anterior, el enunciador pretende compartir una decisión por medio del uso del marcador cachái, es decir, transmitir una información esperando que su interlocutor la comprenda y, en lo posible, emita una opinión al respecto. Además, al utilizar el marcador el emisor refuerza su opinión, dado que presenta razones del porqué de su decisión. Las marcas prosódicas [ $\uparrow]$ indican la entonación ascendente del marcador en el enunciado, dado el predominio de la función de solicitador de aprobación.

\section{7. 'Cachái' como solicitador de aprobación y organizador discursivo}

(8) Entrevistador: Sí, pasa.

M3A7: Como que "ah sí" y así viste dice, un amigo hoy día como cuando la mina, eeeh, la chica es como que quiere así, dice "ah pero vamos a tomar un tecito" ¿SAODcachái? $\uparrow$ No poh es que el loco en volá' quería tomarse un tecito y yo le dije "no, no, tecito va" ¿SAODcachái?^ (risas) y el loco como que no, como que nunca fue así como había sido antes que era como no sé, más tierno más considerado fue como que "ah, ya" como que yo creo que me clasificó como una mina así como que pa' eso.

En el ejemplo el emisor utiliza el marcador conversacional cachái para corroborar que su interlocutor está comprendiendo el enunciado; sin embargo, también utiliza el marcador para narrar una situación, organizando de algún modo los hechos. Las marcas prosódicas [ $\uparrow$ ] indican la entonación ascendente que el enunciador otorgó al marcador, dado el predominio de la función de solicitador de aprobación.

\section{8. 'Cachái' como herramienta argumentativa y organizador discursivo}

(9) Entrevistador: ¿Y después te desempeñaste como chef?

M6B9: Sí, mira, trabajé un, a ver como un par de veces, pero no me gustó, a ver, eh, me hice a cargo de un restaurant que era como, un restaurant nuevo que se había puesto hace poco, pero como que no resultó porque estaba súper mal ubicado, no tenía publicidad, no tenía nada y aparte que los materiales con los que tenía que cocinar eran como malos, de mala calidad, entonces al final nada quedaba rico, HAODcachái $\rightarrow$, como tenían poco presupuesto.

Entrevistador: Claro estaban recién empezando. 
En el ejemplo se puede apreciar el uso del marcador conversacional cachái tanto para reforzar una idea como para organizarla. La organización discursiva se deja ver al cierre del enunciado, puesto que por medio del marcador el hablante inicia la conclusión de este. La marca prosódica [ $\rightarrow]$ da cuenta de la entonación neutra que el hablante dio al marcador.

Por último, Gille, en una observación personal transmitida a las autoras de este trabajo, propone que las funciones del marcador discursivo cachái se pueden distinguir desde dos perspectivas: una concreta y una abstracta. La primera dice relación con la función base del marcador, llamar la atención, y con la función autorreguladora del mismo. La segunda se relaciona con el carácter subjetivo del marcador y tiene relación con la visión compartida de los interlocutores. En esta última perspectiva se encuentran las funciones solicitador de aprobación y herramienta argumentativa. Finalmente, la función que respecta a la organización discursiva se puede dar tanto en la perspectiva concreta como en la abstracta. En este punto es preciso señalar que la función de captador de atención del marcador cachái siempre se encuentra presente. Si bien en algunos casos puede aparecer con la función específica de captador de atención, esta de cualquier modo aparece en todas las demás funciones de forma subyacente. En esto concordamos con Gille, quien señala que el marcador cachái siempre tiene como base la llamada de atención (Gille, 2015a, 2015b).

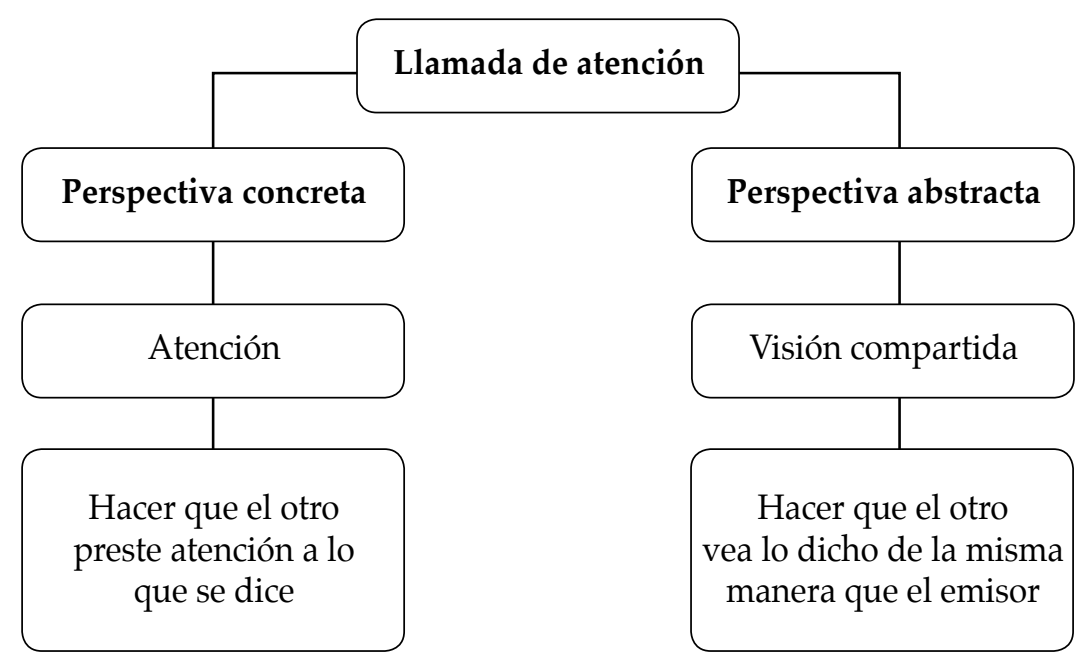

Figura 1. Esquema función base del marcador discursivo cachái. 


\section{Metodología}

El presente estudio se enmarca dentro de un proyecto general sobre el uso de voseo en Chile y su variación en relación a factores internos y externos a la lengua. El método empleado en la investigación para la recopilación de datos corresponde a entrevistas sociolingüísticas en las cuales se considera la estratificación de los informantes según factores como la edad (18-24; 25-34; 35- o más años), el sexo (hombre y mujer) y la procedencia geográfica (cuatro macrozonas delimitadas por el Atlas lingüístico y etnográfico de Chile [Wagner, 1998]). En dicho corpus, la ocurrencia del lexema cachái es muy elevada, pero no en su forma verbal, sino como marcador pragmático-discursivo (Rivadeneira, 2014). Es por esta razón que surgió la inquietud de estudiar los distintos contextos y funciones asignadas a este marcador. Dentro de este enfoque, los objetivos que guían este trabajo son analizar la función pragmática del marcador discursivo en conversaciones semi-espontáneas y determinar si existe incidencia de variables extralingüísticas sobre su empleo. La presente investigación es de corte exploratorio, para lo cual se seleccionaron aleatoriamente 20 archivos transcritos cuyos datos provienen de entrevistas a informantes mayores de 18 años. Cada entrevista tiene una duración aproximada de una hora y un promedio de 15.000 palabras. Para evaluar la variable sexo, se extrajeron datos correspondientes a 10 hombres y 10 mujeres. Así también, para evaluar la variable procedencia geográfica, se tomaron 5 entrevistas por cada zona dialectal: norte, centro, sur y sur austral, las que a su vez contemplan cuatro ciudades: Iquique, Valparaíso, Temuco y Coyhaique, respectivamente. No se consideró la variable extralingüística edad, puesto que lo que se pretendía abordar era el habla oral adulta en Chile a un nivel general. En este punto es importante mencionar que para determinar las diferencias prosódicas del marcador cachái se debió revisar el audio de cada transcripción, debido a que las transcripciones utilizadas para el análisis no daban cuenta de la entonación (ascendente, neutra, descendente) que el hablante daba al marcador y, por ende, la clasificación de la función que estaba cumpliendo cachái se podía asignar erróneamente.

Este estudio además aborda el análisis del marcador discursivo conversacional cachái tanto a nivel cualitativo como cuantitativo. En lo que respecta al análisis cualitativo, se identificaron y definieron las funciones que cumple el marcador en cuestión en el habla oral del 
español de Chile y, en el ámbito cuantitativo, se determinó la frecuencia de uso del marcador cachái en general y para cada una de sus funciones. Además se extrajeron los datos correspondientes a los factores de variación extralingüística, es decir, la frecuencia de uso de cachái según sexo y procedencia geográfica de los informantes.

\section{Análisis y resultados}

El gráfico que se presenta a continuación resume los datos extraídos a partir de la explotación del corpus. Aquí se muestra la frecuencia de uso de cada función identificada para el marcador cachái.

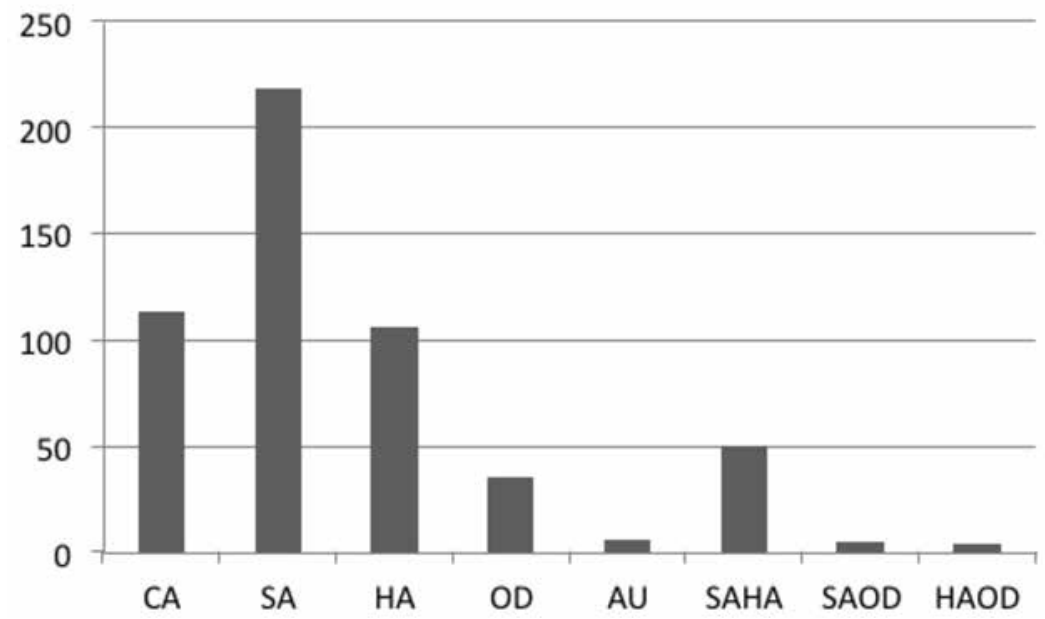

Figura 2. Frecuencia de uso del marcador cachái según su función pragmática.

El gráfico anterior representa estadísticamente la frecuencia de uso para cada función del marcador conversacional cachái, que en el corpus alcanza las 537 ocurrencias. Según los datos, este marcador se utiliza con mayor frecuencia en su función de solicitador de aprobación (SA= 219 ocurrencias), seguida de las funciones captador de atención (CA= 113), herramienta argumentativa $(\mathrm{HA}=106)$ y la función mixta de solicitador de aprobación + herramienta argumentativa $(\mathrm{SAHA}=49)$. Menos frecuentes son las funciones de organizador discursivo $(\mathrm{OD}=$ $35)$, autorregulador $(\mathrm{AU}=6)$ y las mixtas de solicitador de aprobación + organizador discursivo $(\mathrm{SAOD}=5)$ y de herramienta argumentativa + organizador discursivo $(\mathrm{HAOD}=4)$. A modo de ilustración se presentan algunos ejemplos: 
(10) H2B11: No, yo creo que tarde yo terminé mi carrera de profesor, así que no fue-o sea, tendría que resolver primero esos temas.

Entrevistador: Ya.

H2B11: Yo creo que primero llegar a ser profesor fue como todo un desafío, así como, no estuve en un sistema formal, CAcachái $\rightarrow$, tan formal, CAcachái $\rightarrow$.

Entrevistador: Ya.

(11) M7B11: Nunca ehh dije "ahh sí, voy a quedar" no, porque para mí la pega es súper difícil y de hecho a todos se les hacía difícil entrar porque como te digo cuesta mucho entrar al tema porque es súper estructurado todo porque hacen concursos públicos y postulan miles de personas y de todos lados no solamente de acá poh, postulan de todos lados, el solo hecho que es Coyhaique, ¿SAcachái?^

Entrevistador: Sí poh, porque acá ganan caleta de plata.

(12) M7B11: Sí, así es que no-yo nunca me voy a quejar-de que sí igual pasé malos momentos, pero, pero no puedo dejar de reconocer que ahí crecí como persona y aparte aprendí muchas cosas, fue como mi base, mi primer trabajo, porque nunca había trabajado, nunca, o sea, en nada, nunca había trabajado en nada y ahí me sirvió para desenvolverme, para conocer más personas, encontrarme con gente adulta porque igual es distinto, ponte tú, creo que las dos somos como de una edad, ¿qué edad tienes?

Entrevistadora: Tengo veintidós.

M7B11: Eres menor que yo.

Entrevistadora: Sí, soy menor.

M7B11: HAcachái $\downarrow$, es distinto tratar con gente como, así como de nuestra edad a tratar con gente mayor, por sus mañas, ¿SAcachái?

(13) M3A7: Sí, sí así como que el carrete, así como, de la vida, SA ¿cachái? como que nosotros íbamos por las nueve de la mañana, ODcachái $\rightarrow$, como por eh Avenida Esp- Errázuriz, ODcachái $\rightarrow$, como con Chico Trujillo hueón así a to'a raja, ODcachái $\rightarrow$, así en una escalera, o sea en una escalera, en la camioneta todos apretados cantando así como ese *cover que tiene de Mark Anthony, ODcachái $\rightarrow$, o sea "ahora quién si no soy yo". 
Entrevistador: Ah ya.

(14) Entrevistador: Sí igual es complicado idealizar.

M3A7: Si yo digo "no está pa' la cagá ese hombre", si, mucho, AUcachái?, onda, pero en verdad va a pasar ahí el loco como que estaba o sea-

Entrevistador: se va ir aburriendo si es que tú no lo pescai tanto poh.

\subsection{Variable sexo}

A continuación se expone una tabla que muestra la frecuencia de uso del marcador conversacional cachái según la variable extralingüística sexo:

\begin{tabular}{|c|c|c|c|c|c|}
\hline \multirow[t]{2}{*}{ Función } & \multicolumn{2}{|c|}{ Hombres } & \multicolumn{2}{|c|}{ Mujeres } & \multirow[t]{2}{*}{ Totales } \\
\hline & $\begin{array}{l}\text { Frecuencia } \\
\text { de uso }\end{array}$ & $\%$ & $\begin{array}{l}\text { Frecuencia } \\
\text { de uso }\end{array}$ & $\%$ & \\
\hline $\begin{array}{l}\text { Solicitador de } \\
\text { aprobación }\end{array}$ & 129 & 58,9 & 90 & 41,1 & 219 \\
\hline Captador de atención & 57 & 50,4 & 56 & 49,6 & 113 \\
\hline $\begin{array}{l}\text { Herramienta } \\
\text { argumentativa }\end{array}$ & 47 & 44,3 & 59 & 55,7 & 106 \\
\hline $\begin{array}{l}\text { Organizador } \\
\text { discursivo }\end{array}$ & 7 & 20 & 28 & 80 & 35 \\
\hline Autorregulador & 3 & 50 & 3 & 50 & 6 \\
\hline $\begin{array}{l}\text { Solicitador de } \\
\text { aprobación }+ \\
\text { Herramienta } \\
\text { argumentativa }\end{array}$ & 33 & 67,3 & 16 & 32,7 & 49 \\
\hline $\begin{array}{l}\text { Solicitador de } \\
\text { aprobación }+ \\
\text { Organizador } \\
\text { discursivo } \\
\end{array}$ & 3 & 60 & 2 & 40 & 5 \\
\hline $\begin{array}{l}\text { Herramienta } \\
\text { argumentativa } \\
+ \text { organizador } \\
\text { discursivo }\end{array}$ & 4 & 100 & 0 & 0 & 4 \\
\hline Total & 283 & & 254 & & 537 \\
\hline
\end{tabular}

Tabla 1. Frecuencia del uso del marcador cachái según la variable extralingüística sexo. 
Los resultados en cuanto a la diferencia en la frecuencia de uso entre hombres y mujeres, pese a no ser estadísticamente significativa, indican que el marcador conversacional cachái es levemente más utilizado por hombres, lo que respalda lo señalado por San Martín (2011) en su estudio sobre los marcadores interrogativos de control de contacto.

De la información expuesta en la tabla 1 se pueden extraer las siguientes conclusiones generales: la diferencia más marcada entre hombres y mujeres se da en el caso del organizador discursivo (20\% y $80 \%$, respectivamente), seguido de la función mixta solicitador de aprobación + herramienta argumentativa (67,3\% vs. 32,7\%), solicitador de aprobación + organizador discursivo (60\% vs. 40\%) y el solicitador de aprobación en su función simple (58,9\% vs. 41,4\%).

Ahora bien, al observar los datos relativos correspondientes al total de ocurrencias producidas en cada grupo (variación interna), se comprueba igualmente que las diferencias no son muy marcadas en el uso de las distintas funciones, a excepción del organizador discursivo $(2,5 \%$ en hombres y $11 \%$ en mujeres) y el solicitador de aprobación + herramienta argumentativa $(11,6 \%$ vs. 6,3). Estos datos se presentan en la figura 3.

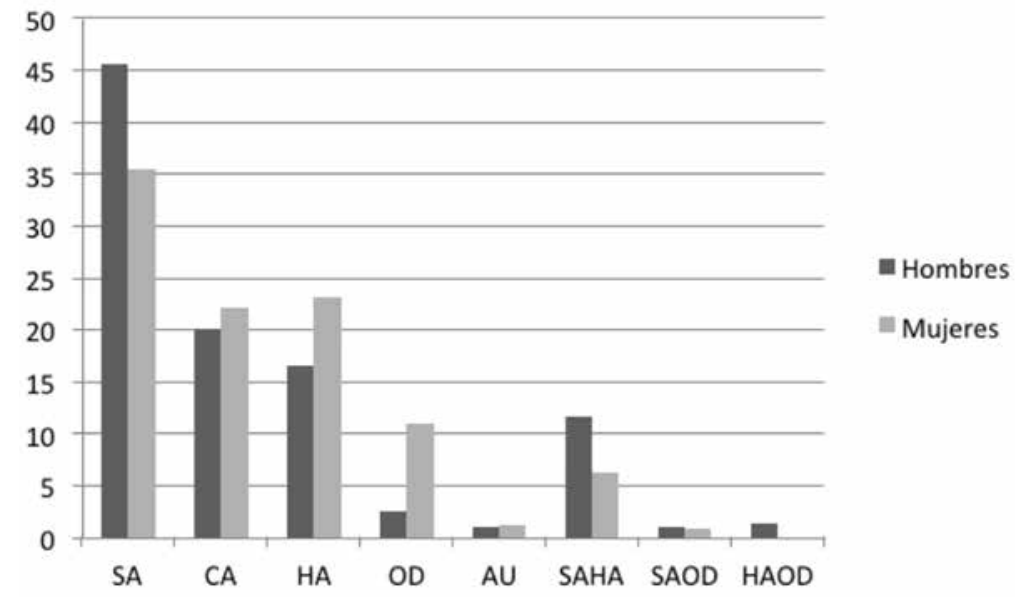

Figura 3. Porcentaje relativo de uso del marcador cachái según función y sexo. 


\subsection{Variable geográfica}

Los resultados de la explotación del corpus según la variable extralingüística procedencia geográfica arrojan lo siguiente:

\begin{tabular}{|c|c|c|c|c|c|c|c|c|c|}
\hline \multirow{2}{*}{ Función } & \multicolumn{2}{|c|}{ Iqq. } & \multicolumn{2}{c|}{ Valp. } & \multicolumn{2}{c|}{ Tco. } & \multicolumn{2}{c|}{ Coy. } & \multirow{2}{*}{ Totales } \\
\cline { 2 - 10 } & Frec. & $\%$ & Frec. & $\%$ & Frec. & $\%$ & Frec. & $\%$ & \\
\hline SA & 79 & 36,1 & 98 & 44,7 & 30 & 13,7 & 12 & 5,5 & 219 \\
\hline CA & 39 & 34,5 & 42 & 37,2 & 24 & 21,2 & 8 & 7,1 & 113 \\
\hline HA & 25 & 23,6 & 37 & 34,9 & 20 & 18,9 & 24 & 22,6 & 106 \\
\hline OD & 9 & 25,8 & 20 & 57,1 & 2 & 5,7 & 4 & 11,4 & 35 \\
\hline AU & 2 & 33,3 & 3 & 50 & 0 & 0 & 1 & 16,7 & 6 \\
\hline SAHA & 23 & 46,9 & 16 & 32,7 & 8 & 16,3 & 2 & 4,1 & 49 \\
\hline SAOD & 0 & 0 & 4 & 80 & 1 & 20 & 0 & 0 & 5 \\
\hline HAOD & 1 & 25 & 2 & 50 & 1 & 25 & 0 & 0 & 4 \\
\hline Total & \multicolumn{1}{|c|}{$\mathbf{1 7 8}$} & \multicolumn{2}{|c|}{$\mathbf{2 2 2}$} & \multicolumn{3}{|c|}{$\mathbf{8 6}$} & & $\mathbf{5 1}$ & $\mathbf{5 3 7}$ \\
\hline
\end{tabular}

Tabla 2. Frecuencia de uso del marcador cachái según variable extralingüística procedencia geográfica.

En primer lugar, como se puede apreciar en la tabla anterior, la mayor concentración de uso del marcador discursivo conversacional cachái se da en la zona central del país, en este caso, representada por la ciudad de Valparaíso, con un total de 222 coincidencias. Además, la zona centro es la única en que se pueden apreciar todas las funciones del marcador, incluyendo las mixtas. En segundo lugar, siguiendo el criterio de frecuencia de uso, se encuentra la zona norte del país representada por Iquique, con un total de 178 coincidencias del marcador en cuestión. En esta zona, se encontraron registros de todas las funciones excepto la función mixta solicitador de aprobación + organizador discursivo. En tercer lugar se encuentra la zona sur del país, representada por la ciudad de Temuco, donde se registró un total de 86 coincidencias para el marcador discursivo cachái. En esta zona no se identificó la función primaria autorregulador. Finalmente, la menor frecuencia de uso para el marcador discursivo cachái se encuentra en la zona sur austral del país, representada por Coyhaique, con un total de 51 coincidencias. En esta zona geográfica no se encontraron registros para dos de las tres funciones 
mixtas asociadas al marcador en cuestión (solicitador de aprobación + organizador discursivo y herramienta argumentativa + organizador discursivo). Además, los datos expuestos en la tabla indican que en las zonas norte (Iquique), centro (Valparaíso) y sur (Temuco) la función con que se utiliza el marcador cachái con mayor frecuencia es la de solicitador de aprobación, mientras que para la zona sur austral (Coyhaique) la función que predomina es la de herramienta argumentativa. A continuación se observan los datos correspondientes a cada ciudad y su variación interna en porcentajes relativos (figuras 4 a 7). La tendencia que se observa es un mayor empleo del marcador en su función de solicitador de aprobación, salvo en la ciudad de Coyhaique, en donde la función de herramienta argumentativa es más preponderante.

\section{Iquique}

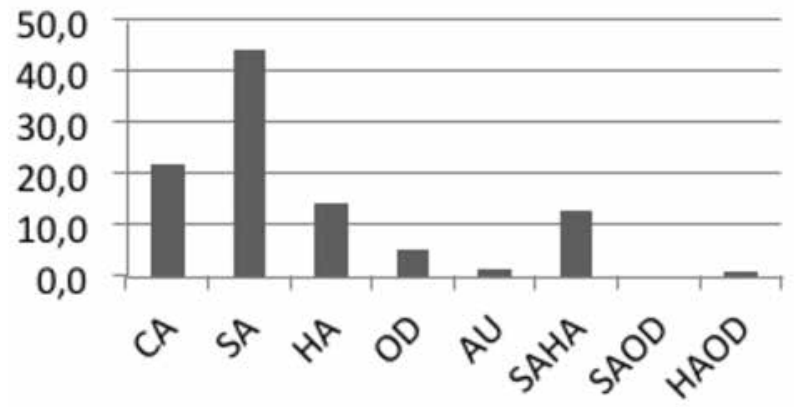

Figura 4. Porcentaje relativo de uso del marcador cachái según función y procedencia geográfica (zona norte). 
Figura 5. Porcentaje relativo de uso del marcador cachái según función y procedencia geográfica (zona centro).

\section{Valparaíso}

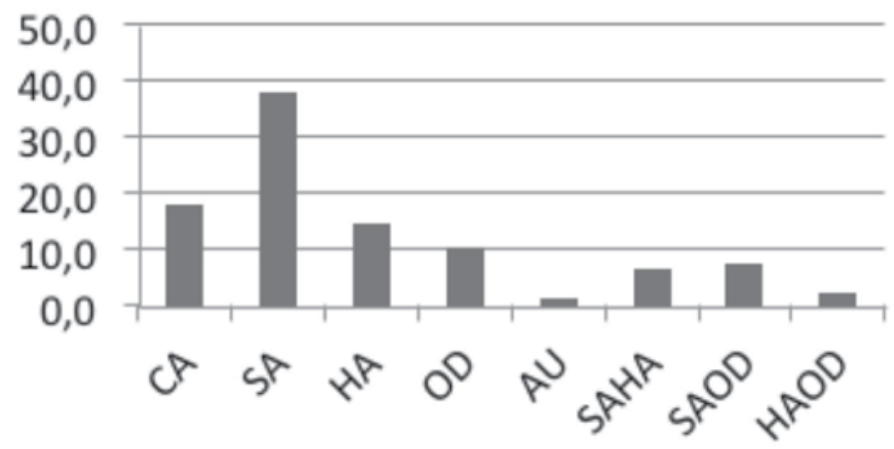

Figura 6. Porcentaje relativo de uso del marcador cachái según función y procedencia geográfica (zona sur).

\section{Temuco}

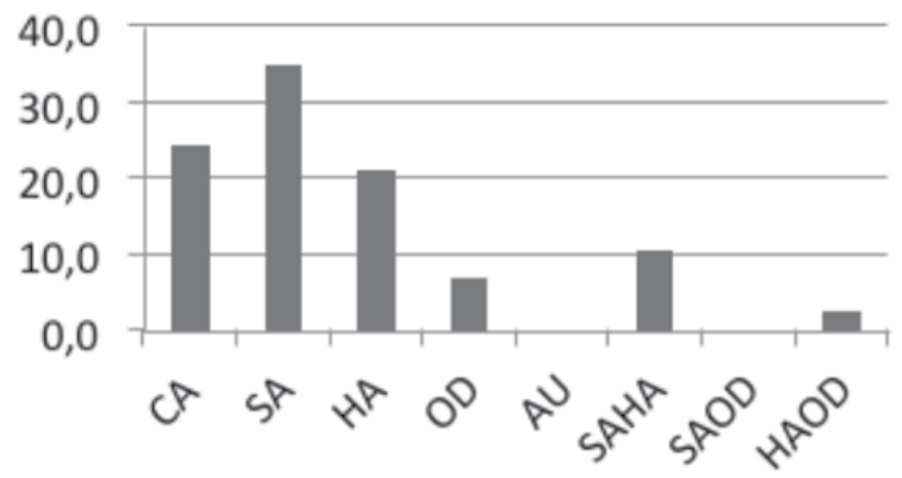


Figura 7. Porcentaje relativo de uso del marcador cachái según función y procedencia geográfica (zona sur austral).

\section{Coyhaique}

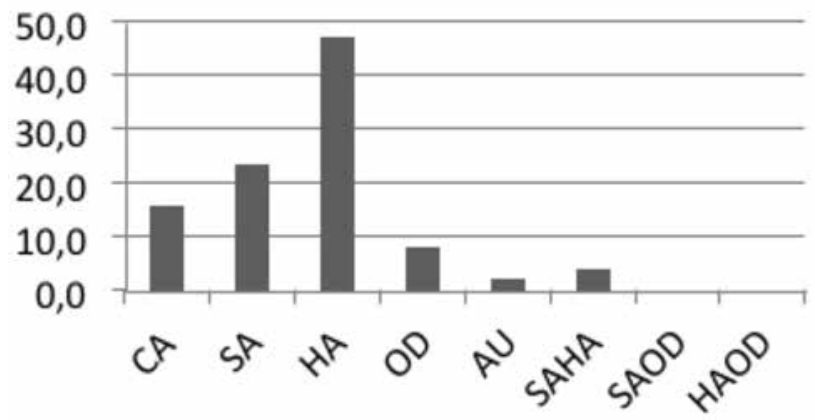

\section{Conclusiones}

Los marcadores discursivos son partículas que aparecen con frecuencia en la conversación y que están sujetas a la influencia de diversos factores. En este estudio se analizaron las diferencias en cuanto a frecuencia de uso y función predominante del marcador cachái según dos variables extralingüísticas: sexo y procedencia geográfica. Los resultados corroboran estudios anteriores que señalan que el marcador conversacional cachái es utilizado por hombres y mujeres, y que su frecuencia de uso es bastante similar entre ambos sexos (San Martín, 2011). Los resultados además dejan de manifiesto que este marcador del discurso es utilizado en todo Chile, independientemente de que su frecuencia de uso varíe según la zona geográfica. Así, la zona centro, representada en el corpus por la ciudad de Valparaíso, presenta mayor ocurrencia del marcador. A esta le sigue Iquique (zona norte), Temuco (sur) y Coyhaique (sur-austral). Cabe señalar que esta misma distribución geográfica se da para el uso de voseo en Chile (Rivadeneira, 2009 y 2014; Rivadeneira y Clua, 2011).

Por otro lado, mientras otros enfoques le dan más relevancia al turno de habla (Gille, 2013a, 2015a, 2015b), en este trabajo hemos querido optar por una propuesta alternativa que da cuenta, además, de la variación en el nivel pragmático-discursivo. Así, se puede concluir que existe 
una amplia gama de funciones que cumple el marcador cachái según el contexto lingüístico en el que se da, distinguiéndose categorías con distintas dimensiones. Si bien todas las funciones de cachái tienen como base el captar la atención, es posible diferenciar categorías básicas como la de solicitador de aprobación, herramienta argumentativa, organizador discursivo y autorregulador. Asimismo, se comprueba que existen casos con más de una función, como solicitador de aprobación + herramienta argumentativa, solicitador de aprobación + organizador discursivo y herramienta argumentativa + organizador discursivo. La propuesta de funciones de cachái que se presenta aquí parece ajustarse de manera adecuada a los datos de habla semi-espontánea analizados en el corpus.

La investigación realizada, al ser de carácter exploratorio, puede ser considerada como un primer acercamiento hacia el estudio de las distintas funciones que cumple el marcador conversacional cachái considerando variables geo y sociolingüísticas. Es por eso que es pertinente señalar que los resultados obtenidos en el presente estudio no deben considerarse como definitivos, sino que pueden ser complementados y cotejados con investigaciones futuras. De este estudio podemos concluir que cachái es un marcador discursivo conversacional que cumple funciones concretas. Se demuestra que este marcador no es utilizado como simple muletilla, sino que cumple diversos propósitos, dependiendo de cuál sea la intención que se pretende transmitir en los enunciados.

Para finalizar, a nivel sociolingüístico cabe recalcar que cachái es una partícula discursiva característica y distintiva del español de Chile, factor que debería ser considerado como una motivación para realizar más estudios, en lo posible con datos que abarquen zonas geográficas más extensas y que permitan lograr un enfoque más general sobre el uso de este rasgo a nivel dialectal. 


\section{Bibliografía}

Academia Chilena de la Lengua. (2010). Diccionario de uso del español de Chile. Santiago: Asociación de Academias de la Lengua Española.

Benavides, C. (2003). La distribución del voseo en Hispanoamérica. Hispania, 86(3), 612-623.

Briz, A. (1998). El español coloquial en la conversación: esbozo de pragmagramática. Barcelona: Ariel.

Briz, A. (2001). El español coloquial en la conversación: esbozo de pragmagramática (2da edición). Barcelona: Ariel.

Cerny, J. (1999). Observaciones sobre el español hablado en América. Acta Universitatis Palackianae Olomucensis, Facultas Philosophica, Philologica 74, Romanica Olomucensia VIII, Iberoamericana Olomucensia I (pp. 39-48). Olomouc: Univerzita Palackého v Olomouci.

Cid, M. y Poblete, M. (1999). Marcadores pragmáticos en el español culto de Santiago de Chile: aspectos prosódicos. Onomazein, 4, 103-123.

Corominas, J. (1954). Diccionario crítico etimológico de la lengua castellana. Madrid: Gredos.

Gille, J. (2013a). Sobre el uso de los marcadores discursivos cachái, viste y te fijái al inicio de turno. En Pardo, N. G., García, D. E., Oteiza S, T. y Asqueta C., M. C. (Eds.), Estudios del discurso en América Latina, (pp.465-483). Bogotá: Asociación Latinoamericana de Estudios del Discurso.

Gille, J. (2015a). On the development of the Chilean Spanish discourse marker cachái. Revue Romane, 50(1): 3-29.

Gille, J. (2015b). Los apéndices conversacionales en la argumentación: el caso de ¿cachái? En Engwall, Gunnel y Fant, Lars (Eds.), Festival Romanística 1, Stockholm Studies in Romance Languages, (pp. 239-258). Stockholm: Stockholm University Press. 
González, C., Meneses, A. y Unda, V. (2000). Análisis de la relación entre estructuras sintácticas y marcadores discursivos en la conversación semiespontánea de adolescentes santiaguinos. Formulación de un proyecto de investigación. Onomázein, 5, 333-346.

Lenz, R. (1905). Diccionario etimológico de las voces chilenas derivadas de lenguas americanas. Santiago de Chile, Seminario de filología hispánica, Universidad de Chile.

Martín Zorraquino, M.A. y Portolés, J. (1999). Los marcadores del discurso. En I. Bosque, y V. Demonte, (Eds.), Gramática descriptiva de la lengua española (pp.40514212) (Vol. 3). Madrid: Espasa Calpe.

Méndez, A. y Mondaca, L. (2014). “'No es muletilla, es marcador, cachái?’. Análisis de la función pragmática del marcador discursivo conversacional cachái en el español de Chile. Posibles equivalentes en inglés". Tesis de licenciatura, Universidad Católica de Temuco.

Meneses, A. (2000). Marcadores discursivos en el evento "conversación". Onomázein, 5, 315-331.

Móccero, M. L. (2010). Las preguntas confirmatorias como indicadoras deposicionamiento intersubjetivo. Estudios Filológicos, 45, 67-78.

Poblete, M.T. (1998). Los marcadores discursivo-conversacionales de más alta frecuencia en el español de Valdivia (Chile). Estudios Filológicos, 33, 93-103.

Pons, H. y Samaniego, J. (1998). Marcadores pragmáticos de apoyo discursivo en el habla culta de Santiago de Chile. Onomazein 3, 11-25.

Portolés, J. (2001). Marcadores del discurso. (2da ed.). Barcelona: Ariel Practicum.

Rabanales, A. y Contreras, L. (1995). Las muletillas en el habla culta de Santiago de Chile. En Scripta Philologica in honorem Juan M. Lope Blanch (Vol. 2, pp. 673-744). México: UNAM. 
Rivadeneira, M. (2009). El voseo en medio de comunicación de Chile. Descripción y análisis de la variación dialectal y funcional. Tesis doctoral, Universitat Pompeu Fabra.

Rivadeneira, M. y Clua, E. (2011). Una visión desde el análisis de la variación dialectal y funcional en medios de comunicación. Hispania, 94(4), 680-703.

Rivadeneira, M. (2014). '¡Eríh buena onda!' La variación sociolingüística y discursiva del voseo en el habla espontánea y semi-espontánea de Chile. Comunicación en XVII Congreso Internacional de la Asociación de Lingüística y Filología de América Latina (ALFAL), Universidade Federal da Paraíba, João Pessoa-Brasil, 15-19 julio.

Rodríguez, F. (2009). Estudio sobre las funciones pragmadiscursivas de ¿no? Y ¿eh? En el español hablado. Revista de Lingüística Teórica y Aplicada, 47(1), 83-101.

San Martín, A. (2011). Los marcadores interrogativos de control de contacto en el corpus PRESEEA de Santiago de Chile. Boletín de Filología, XLVI(2),171-199.

Valencia, A. (2014). Marcadores del discurso de Santiago de Chile. Cuadernos de la ALFAL, 5, 246-276.

Wagner, C. (1998). El atlas lingüístico y etnográfico de Chile por regiones (ALECh). Estudios Filológicos, 33, 119-129. 